\title{
Electrodeposition and Characterization of Mesoporous Nanostructured Cobalt Films
}

\author{
Ahmed A. Al Owais ${ }^{1}$, Ibrahim S. El-Hallag ${ }^{2, *}$, Elsayed El-Mossalamy ${ }^{3}$ \\ ${ }^{1}$ Chemistry Department, College of Science, King Saud University, Riyhad, Saudi Arabia \\ ${ }^{2}$ Chemistry Department, Faculty of Science, Tanta University, Tanta, Egypt. \\ ${ }^{3}$ Chemistry Department, Faculty of Science, Benha University, Benha, Egypt. \\ *E-mail: i.elhallag@yahoo.com
}

doi: $10.20964 / 2020.08 .77$

Received: 20 February 2020/ Accepted: 14 May 2020 / Published: 10 July 2020

In this article we demonstrate a simple and versatile technique for the fabrication of mesoporous films of cobalt using Brij-76 surfactant which is used as the template for exhibiting the three-dimensional highly ordered deposited films. It was found that the films containing arrays are closed and packed in a uniform size and spherical holes. Here the mesoporous cobalt films were prepared electrochemically. Also, different potential techniques were used for investigation and description the properties of the plated mesopores of Co films.

Keywords: Nanostructured, mesoporous, Electrodeposition, Brij76, Cyclic voltammetry.

\section{$\underline{\text { FULL TEXT }}$}

(C) 2020 The Authors.Published by ESG (www.electrochemsci.org). This article is an open access article distributed under the terms and conditions of the Creative Commons Attribution license (http://creativecommons.org/licenses/by/4.0/). 